\title{
CAULES DE SPHENOPHYTA DA FORMAÇĀO RIO DO RASTO (BACIA DO PARANÁ, PERMIANO SUPERIOR) $)^{1,2}$
}

\author{
Rosemarie Rohn ${ }^{3}$ \\ Oscar Rösler
}

\begin{abstract}
Sphenophyte stems have been studied from 28 new outcrops of the Rio do Rasto Formation (Passa Dois Group, Paraná Basin, Upper Permian) in Paraná and Santa Catarina States. Four new, informally described species of Paracalamites are recognized, each corresponding to a different basic morphologic stem type. Paracalamites sp. 1, $P$ sp. 2 and $P$. sp. 3 are preserved as pith cavity casts, probably having calamitacean affinities. These species exhibit well-preserved fascicular and interfascicular areas and are differentiated by their respective cellular patterns in interfascicular areas (corresponding to the medullary rays), nodal region characteristics and morphometric values. Many features considered important in these species are not included in the diagnoses of Paracalamites australis Rigby and $P$. levis Rigby, the two species in which practically all isolated sphenophyte pith cavity casts from Gondwana are generally placed. Paracalamites sp. 2 and $P$. sp. 3 present internal evidence of branch insertions. Paracalamites aff. P. sp. 1 shows possible "Williamson infranodal canals". Some internal casts of Paracalamites sp. 2 are covered by thin films (molds) exhibiting cell impressions, which probably represent more external tissues of the stem. "Paracalamites" sp.4 is mainly characterized by external surface features, including possible leaf sheaths, in one case intima. tely associated with the pith cavity cast. This species is similar only to stems from Lidgetton (South Africa), as yet not formally classified, supposedly having equisetacean rather than calamitacean affinities. The South African stems, some stems of Phyllotheca indica Bunbury and those reported in this paper are the only reasonably well preserved and adequately described Gondwanic sphenophyte stems. Detailed studies of more carefully collected material will probably provide many clues as to the evolution and systematics of the Sphenophyta.
\end{abstract}

\section{INTRODUÇÃo}

As esfenófitas, vegetais de caules articulados, foram relativamente comuns no Paleozói. co Superior, inclusive na regiāo gondvânica. Existem numerosas espécies descritas, fundamentadas geralmente nas características das fothas ou das frutificações. Entretanto, sempre houve dificuldade na classificação dos caules fósseis isolados, os quais frequentemente săo muito semelhantes entre si, não refletindo tāo claramente as diferenças taxonômicas reveladas pelos órgăos foliares ou frutificaçōes. Para estes caules desprovidos de folhas ou de frutificaçōes, com exceção daqueles mineralizados, criou-se morfogèneros baseados fundamentalmente nas posiçōes relativas das áreas fasciculares e das interfasciculares nos entrenós sucessivos, preservados como moldes de cąidade da medula. Em resumo, os principais gêneros estabelecidos, inicialmente para as regiōes extragondvânicas, são Calamites e Paracalamites. No primeiro, as áreas fasciculares $e$ as interfasciculares alternam-se na passagem dos nós, enquanto que em Paracalamites nāo se verifica tal alternância. Ainda há outros gêneros, de menor relevância para este trabalho, como Archaeocalamites, Neocalamites, etc.

Até recentemente, os caules isolados de esfenófitas đa regiâo gondvânica têm sido classificados como Phyllotheca ou Schizoneura, apesar destes gêneros terem sido estabelecidos com base em folhas conectadas a caules. RIGBY (1966), verificando que todos estes caules coadunam com o morfogénero Paracalamites criado por ZALESSKY (1927) para formas da região angárica, erigiu as novas espécies $P$. australis e $P$. levis para caules simples, sem tubér-

1 Contribuiçāo ao Projeto nọ 237 ("Gondwana Floras") do Programa Internacional de Correlaçäo Geologica, IUGS-UNESCO.

2 Trabalho realizado com o apoio financeiro da FAPESP (Proc. No 83/2220-0).

3 Pós-Graduanda do IG-USP e Bolsista da FAPESP (Proc. No 82/2096-5).

4 IG-USP. 


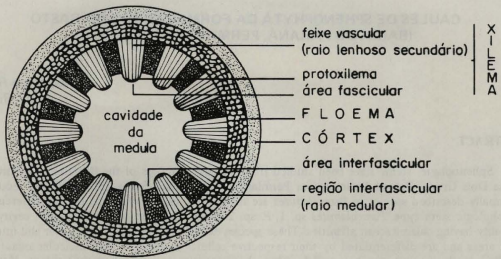

Figura 1 - Representaçło esquemática de corte transversal em caule hipotético de esfenófita (baseada em BOUREAU, 1964).

culos, apresentando entrenós respectivamente mais longos ou mais curtos que o seu "diâmetro". RIGBY (1966), ao mencionar o "diâmetro" do caule, certamente está se referindo à largura do molde medular do caule, a qual é aproximadamente igual à metade do seu diámetro original, a julgar pelas ilustrações apresentadas por este autor para as citadas espécies. Desde o trabalho de RIGBY (1966), com algumas exceçōes, como P. montemorensis do Subgrupo Itararé de São Paulo (MILLAN, 1966), os nomes $P$. levis e principalmente, $P$. australis tèm sido aplicados a todos os caules de esfenófitas gondvânicos, independentemente da sua posição estratigráfica.

Caules de esfenófitas da Formação Rio do Rasto foram mencionadas por OLIVEIRA (in HOLDHAUS, 1918), DOLANITI $(1945,1952)$. MENDES (1954), RIGBY (1970) e sumariamente descritos por BORTOLUZZI (1975), como Paracalamites sp., por CAZZULO-KLEPZIG (1978) e por CAZZULO-KLEPZIG \& COR. REIA (1981), como Paracalamites australis. RÖSLER \& ROHN (1984), num trabalho sobre Sphenophyllum da Formação Rio do Rasto. incluíram a descrição de alguns caules isolados relacionados a este gênero, sendo bastante dis. tintos de Paracalamites.

No presente trabalho, são analisados 73 exemplares de caules isolados de esfenófitas (de um total de 128 coletados) procedentes de 28 afloramentos (de um total de 49 em que foram constatados) da Formaçāo Rio do Rasto do Estado do Paraná e de Santa Catarina. Há pelo menos quatro tipos de caules, preliminarmente classificados como Paracalamites sp. 1, P. sp.2.
$P$. sp. 3 e $P$. sp. 4 . É válido ressaltar que a subdi. visão dos caules em quatro tipos fundamentais é relativamente consistente, porém artificial pela impossibilidade de utilização de critérios naturais de classificação. Estes caules são distintos de Paracalamites australis ou de $P$. levis por apresentarem uma série de particularidades (possiveis tubérculos, cicatrizes de ramos, etc.) que são apontadas como inexistentes na diagnose original destas espécies, além da preservação de células, náo observadas por RIGBY (1966) e por outros autores. Detalhes equivalentes em caules gondvânicos foram apenas constatados por PANT \& KIDWAI (1968) para Phyllotheca indica da India e por GORDON-GRAY et al. (1976) para caules nāo classificados da África do Sul.

Esta pesquisa faz parte de um projeto mais amplo sobre a bioestratigrafia e paleoam. biente da Formação Rio do Rasto, para o qual já estão concluídos diversos trabalhos (vide ROHN \& RÖSLER, 1986).

\section{MATERIAL E LOCALIDADES FOSSILIFERAS}

Os caules estāo preservados como moldes comprimidos da cavidade da medula e como moldes provavelmente externos. Os fósseis ocorrem majoritariamente em argilitos e siltitos. às vezes com carbonato de cálcio, em geral, pra. ticamente maciços, incipientemente rítmicos com laminação gradacional, compactos, com fratura conchoidal (dificultando a obtençăo de amostras com fósseis expostos em áreas grandes) ou com ligeira laminação plano-paralela. 
Mais raramente, os fósseis ocorrem em arenitos finos. Em quase todas as litologias há casos de boa preservaçāo dos detalhes, e de contraste cromático entre as estruturas e a matriz.

Os afloramentos de coleta listados abaixo foram designados segundo a sigla AF/GP utilizada pelo Departamento de Paleontologia e Estra. tigrafia do Instituto de Geociências da Universi. dade de São Paulo. Além da localização, são fornecidas algumas informaçōes resumidas sobre as litologias. As amostras estáo depositadas na coleçāo paleontológica do mesmo departamento sob a sigla GP/3T

\section{Lista de localidades}

- AF/GP 36 - estrada Lauro Müller-São Jaaquim da Serra, km 15,9, SC (localidade-tipo do Membro Morro Pelado); siltitos argilosos a siltitos arenosos cor-de-vinho, moderadamente alterados; Paracalamites sp., exemplar GP/3T 1677 (não descrito no presente trabalho).

- AF/GP 168 - estrada Rondinha-Paulo Frontin, a cerca de $400 \mathrm{~m}$ da BR 476, niveis 1,3 , 4 e 5 , PR; argilitos cor-de-vinho; Paracalamites sp. 2 .

- AF/GP 169 - estrada Rondinha-Paulo Frontin, a cerca de $13 \mathrm{~km}$ ao sul de Paulo Frontin. PR; argilito cor-de-vinho; Paracalamites ef. P. sp.2.

- AF/GP 171 - BR 277, aproximadamente km 310,5, PR; argilito róseo-creme; Paracalamites sp.2.

- AF/GP 172 - trevo BR 277 - BR 373, 2 niveis, PR; siltito cinza e siltito cor-de-vinho; Paracalamites sp. 1, Paracalamites sp.2.

- AF/GP 174 - BR 376 (Rod. do Café), km 292, PR; siltito cinza-amarelado; Paracalamites $\mathrm{sp} .3$.

- AF/GP 175 - BR 376, km 288, PR; argilito cor-de-vinho; Paracalamites cf. $P$. sp. 2 .

- AF/GP 176 - estrada Reserva-Cândido de Abreu, a cerca de $59,8 \mathrm{~km}$ de Reserva, PR; argilito cor-de-vinho escuro; Paracalamites sp.

- AF/GP 177 - BR 476, km 203, PR; argilito cor-de-vinho; Paracalamites aff. P.sp.1.

- AF/GP 179 - BR 476, aproximadamente km 207,2, PR; argilito cor-de-vinho; Paracalamites sp.

- AF/GP 180 - BR 476, aproximadamente km 218, PR; argilito cor-de-vinho; Paracalamites sp.

- AF/GP 181 - estrada Paula Freitas - BR 476 , a cerca de $2,3 \mathrm{~km}$ a oeste da estação ferroviária de Paula Freitas, PR; argilito cor-devinho; Paracalamites sp. 2.
- AF/GP 182 - BR 476, km 221,2 PR; argilito cor-de-vinho: Paracalamites sp. 2.

- AF/GP 183 - estrada Poço Preto-Porto Uniāo, a cerca de $200 \mathrm{~m}$ a leste do Rio Timbó, SC; argilito siltoso a arenito muito fino cor-de-vinho; Paracalamites sp.2, Paracalamites cf. $P$. sp. 3 .

- AF/GP 184 - estrada Poço Preto-Porto Uniāo, a cerca de $12,5 \mathrm{~km}$ a oeste do Rio Timbó, SC; siltito arenoso roxo e verde; $\mathrm{Pa}$. racalamites $\mathrm{cf} . P$. $\mathrm{sp} .2$.

- AF/GP 185 - estrada Rondinha-Paulo Fron. tin, a cerca de $16,8 \mathrm{~km}$ a sul de Paulo Frontin. PR, nível 2 ; argilito siltoso alterado esverdeado; Paracalamites sp. 2 ; Paracalamites cf. $P$. sp. 1 .

- AF/GP 187 - estrada Rondinha-Paulo Frontin, a cerca de $7,3 \mathrm{~km}$ a sul de Paulo Frontin, PR; argilito cor-de-vinho; Paracalamites sp.

- AF/GP 189 - estrada Paulo Frontin-Rio Azul, a cerca de $9,0 \mathrm{~km}$ a sul de Dorizon, PR; siltito argiloso cinza; Paracalamites sp. 2.

- AF/GP 191 - BR 277, km 294, PR; argilito siltoso cor-de-vinho; Paracalamites sp. 2.

- AF/GP 197 - BR 373, aproximadamente km 103,8, PR; siltito argiloso alterado amarelo-rosa-esverdeado; Paracalamites sp.4.

- AF/GP 198 - BR 373, aproximadamente $\mathrm{km} 104,4$, PR; arenito muito fino; Paracalamites sp. 2 .

- AF/GP 199 - estrada Reserva-Cândido de Abreu, de 29,1 a 29,7km de Reserva, PR; siltito cor-de-vinho; Paracalamites sp.

- AF/GP 201 - estrada Reserva-Cândido de Abreu, a $33,7 \mathrm{~km}$ de Reserva, PR; siltito argiloso cinza escuro; Paracalamites sp.

- AF/GP 205 - estrada Reserva-Cândido de Abreu, de 41,1 a 41,3km de Reserva, PR; siltito roxo; Paracalamites sp.

- AF/GP 206 - estrada Reserva-Cândido de Abreu, de 44,6 a $45 \mathrm{~km}$ de Reserva, PR, 3 niveis; siltito argiloso cor-de-vinho e siltito argiloso roxo-acinzentado; Paracalamites sp.

- AF/GP 207 - estrada Reserva-Cândido de Abreu, a cerca de $45,4 \mathrm{~km}$ de Reserva, PR; siltito argiloso roxo; Paracalamites sp.

- AF/GP 209 - estrada Reserva-Cândido de Abreu, a cerca de $54,2 \mathrm{~km}$ de Reserva, PR. siltito argiloso cor-de-vinho arroxeado, $\mathrm{Pa}$ racalamites $\mathrm{sp}$.

- AF/GP 210 - BR 376 (Rod. do Café), km 264,6, PR, nível 2; siltito cinza; Paracalamites sp. 2, Paracalamites sp. 3 .

- AF/GP 217 - BR 376, km 273,4, PR; siltito roxo; Paracalamites sp.

- AF/GP 218 - BR 376, km 273,8, PR; siltito arenoso com carbonato de cálcio; Paracalamites sp. 
- AF/GP 219 - BR 376, km 274, PR; siltito cor-de-vinho avermelhado; cf. Paracalamites sp.

- AF/GP 220 - BR 376, km 277,2, PR; siltito argiloso cor-de-vinho; Paracalamites sp. 2 .

- AF/GP 222 - BR 376, km 291,4, PR; siltito argiloso cor-de-vinho; Paracalamites sp.

- AF/GP 223 - BR 376, km 296, PR; siltito arenoso cor-de-vinho bastante alterado: $P a$ racalamites $\mathrm{sp}$.

- AF/GP 224 - BR 376, km 296,6, PR; siltito argiloso a argilito verde claro ou cinza; Paracalamites cf. $P .5 \mathrm{~s} .2$.

- AF/GP 226 - PR 90 (Rod. Sapopema-São Jerônimo da Serra), aproximadamente km 117,1, PR; siltito arenoso cor-de-vinho arroxeado; Paracalamites sp.

- AF/GP 227 - PR 90, aproximadamente km 118,8, PR; siltito roxo; Paracalamites sp. 2.

- AF/GP 229 - PR 90, km 120, PR; siltito argiloso roxo a alterado amarelado; Paracalamites sp.

- AF/GP 240 - estrada Ribeirão do PinhalJundiaí do Sul, a cerca de $6,7 \mathrm{~km}$ de Ribejrão do Pinhal, PR; arenito fino cor-de-vinho; Paracalamites of. $P$. sp. 2.

- AF/GP 249 - BR 153, próximo ao trevo de Santo Antônio da Platina, aproximadamente $\mathrm{km} \mathrm{41,7,2}$ niveis, PR; siltito cinza-avermethado $\mathrm{e}$ arenito fino amarelo; Paracalamites sp.2, Paracalamites sp.

- AF/GP 251 - BR 153, km 44, nível 1, PR; siltito cinza esverdeado com gretas de contração; Paracalamites sp.

- AF/GP 269 - BR 277, km 308, PR; argilito cor-de-vinho; Paracalamites sp.

- AF/GP 271 - BR 277, aproximadamente km 294,4, PR; siltito argiloso esverdeado ou rosado quando al terado; Paracalamites sp.

- AF/GP 278 - estrada Mallet-Dorizon, a cerca de $3,4 \mathrm{~km}$ a sul de Mallet, PR, siltito argiloso cor-de-vinho; Paracalamites sp.

- AF/GP 282 - BR 470, aproximadamente km 207,5, SC; siltito cinza e siltito argiloso róseo; Paracalamites sp. 2.

- AF/GP 284 - estrada retificada ReservaCåndido de Abreu, a cerca de $34 \mathrm{~km}$ de Reserva, PR; arenito fino esbranquiçado; Paracalamites $\mathrm{sp}$.

- AF/GP 303 - BR 376, km 284,6, PR, siltito arroxeado; Paracalamites sp.

- AF/GP 306 - PR 90, km 119,4, PR; siltito arenoso cinza; Paracalamites cf. $P$. sp. 2 .

- AF/GP 307 - PR 90, km 122, PR, nível a siltito argiloso cor-de-vinho; Paracalamites sp. 2 ; nível $\mathrm{c}$ - siltito argiloso amarelo; Paracalamites cf. $P$. sp. 2.

\section{SISTEMẢTICA}

Divisão SPHENOPHYTA

Classe SPHENOPSIDA

Ordem EQUISETALES

Familia incerta

Gênero Paracalamites Zalessky, 1927

\section{Paracalamites sp.1}

Figs. 2, 6 a 9

Material estudado e procedência - AF/ GP $172-$ GP/3T 1653a/b, 1654, 1655, 1656, $1657 \mathrm{a} / \mathrm{b}, 1658,1659,1660$; exemplar considerado como Paracalamites cf. $P$. sp.1: AF/GP $185-$ GP/3T $1639 \mathrm{bB}$.

Descriçāo - Os moldes (e as respectivas contra-impressōes) da cavidade da medula dos caules articulados considerados como Paracala. mites sp.1, evidenciam entrenós relativamente curtos, de comprimento igual a $7,6 \mathrm{~mm}$ a mais de $30,6 \mathrm{~mm}$, em mé đia $18,2 \mathrm{~mm}$; a largura máxima das porçōes expostas dos caules é igual a $51,3 \mathrm{~mm}$, porém provavelmente podendo exceder muito este valor.

As impressões das áreas fasciculares e das interfasciculares praticamente não exibem diferença de relevo, impossibilitando o reconhecimento de seus limites exatos, a não ser nas proximidades dos nós ou nos caules de entrenós muito curtos (Fig. 7). As áreas interfasciculares situam-se em posiçāo opos ta ou quase oposta na passagem dos nós, sendo alternas apenas nas regiōes de aumento ou de diminuiçẫo do número de áreas interfasciculares e fasciculares de um entrenó para o outro (Figs. 6,9). A relaçåo entre a largura das áreas fasciculares e a das interfasciculares é igual a $1: 1,7$ a $1: 2,6$, atingindo, no exemplar de entrenó mais curto (GP/3T 1660 , Fig, 7), a razão $1: 5,4$. Ao longo de uma linha transversal aos entrenós, verificou-se 3,4 a 5,7 áreas fasciculares (ou interfasciculares) $/ \mathrm{cm}$, sendo este índice aproximadamente proporcional ao comprimento dos entrenós (valores maiores correspondendo aos entrenós mais longos). No espécime GP/3T 1654, as áreas interfasciculares aparentemente dispōem-se um pouco imbricadas sobre as fasciculares.

Nas áreas interfasciculares da região média dos entrenós, há impressões de células retangulares alongadas e perfeitamente alinhadas longitudinalmente (aproximadamente com 0,10 a $0,15 \mathrm{~mm}$ de largura e 0,40 a $0,60 \mathrm{~mm}$ de comprimento, porém mais curtas e um pouco mais largas em direçāo aos nós; Figs. $8 \mathrm{~b}, \mathrm{c}$ ).

As áreas fasciculares são representadas por 5 ou 6 estrias delimitando faixas de largu- 
Paleobot. e Palinol. na América do Sul - 1985 - Bol. IG-USP, Inst. Geociènc., Univ. S. Paulo, 17: 1-147, 1986

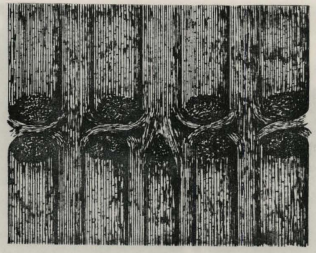

Figura 2 - Esquema da região nodal no molde da cavidade da medula em Paracalarnites sp. $1 ;$ escala $=4 \mathrm{~mm}$.

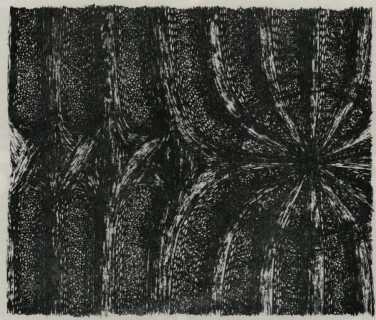

Figura 3 - Esquema interpretativo da região nodal no molde da cavidade da medula em Paracalamites sp.2 com uma estrutura respectiva a insercăo de ramo; escala $=4 \mathrm{~mm}$.
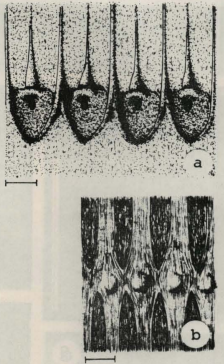

Figura 4 - Esquema de $P$ a. racalarnites sp. 4 : (a) impress ब̌o da superfície externa do caule com moldes de bases foliares na re. giāo nodal, (b) regiāo nodal de moide da cavidade da medula lconforme exemplar GP/3T $1667 \mathrm{bD}$, considerado como Paracalamites of. P. sp.4), escala = $4 \mathrm{~mm}$.

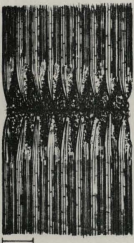

Figura 5 - Esquema do molde da cavidade da medula de Paraca/amites sp. 3 ; escala $=4 \mathrm{~mm}$. 

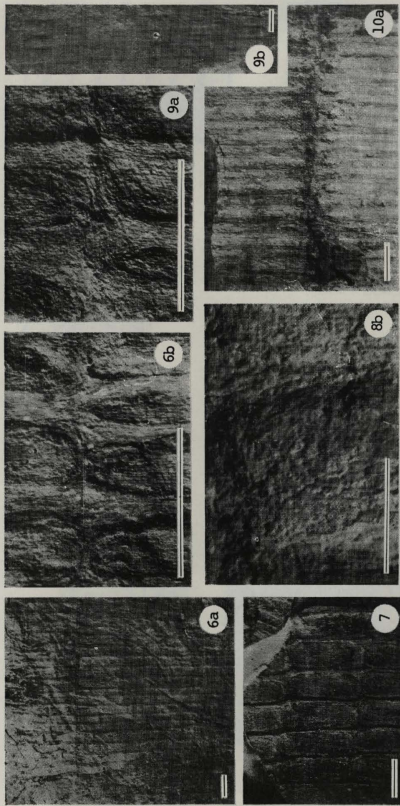

2.

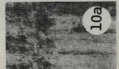

sitis: (5)
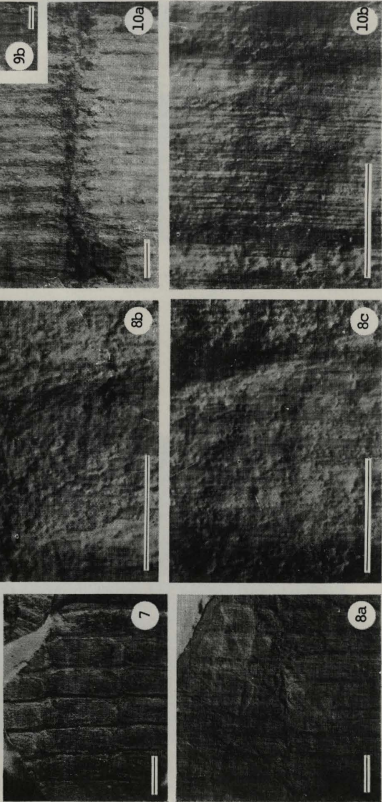
ra semelhante à das células das áreas interfasci. culares; linhas transversais às estrias aparentemente estão ausentes.

Os nós são bem marcados. A linha nodal é estreita e retilinea, aproximadamente com 0,3 a $0,5 \mathrm{~mm}$ de largura, ligeiramente deprimida nas impressōes. As áreas interfasciculares nāo apresentam modificaçōes da largura até bem próximo aos nós, aparecendo apenas um pouco arredondadas nas extremidades. As áreas fasciculares alargam-se muito pouco na regiāo dos nós, aparentemente subdivindindo-se em três bandas: a parte central das áreas fasciculares permanece retilínea; cada banda lateral tem seu curso desviado para aproximadamente uma senóide na regiđo nodal, determinado pela passagem entre a área interfascicular adjacente e a respectiva área interfascicular oposta do entrenó seguinte, contornando parcialmente as duas extremidades (Figs. 2, 6b, 9a). Nas impressōes, a banda esquerda sempre sobrepōe a direita no espaço entre cada par de áreas interfasciculares opostas (portanto, na parede da cavidade da medula original do caule, a banda direita sobrepōe a esquerda) (Fig. 9a). De um entrenó para o outro pode haver supressão de uma área interfascicular ou aparecimento de uma nova área interfascicular, sendo possiveis os dois casos numa mesma regiāo nodal (exemplar GP/3T $1653 \mathrm{a} / \mathrm{b}$, Figs, 6a, b). Na região com uma área interfascicular a menos há compensação por uma larga área fascicular formada pela fusão de duas áreas fasciculares (seis bandas). No outro entrenó, respectivamente a esta área fascicular larga, ocorre uma área interfascicular com extremidade mais estreita e aguda que as outras áreas interfasciculares próximas (Figs. 6b, 9a).

Em caud área interfascicular existe uma porção mais ou menos circular a elíptica (aproximadamente com 0,5 a $0,9 \mathrm{~mm}$ de diâmetro ou comprimento), nem sempre bem evidente, ocupando praticamente toda a sua extremidade. O limite das porçōes elípticas geralmente é formado por células alongadas, um pouco mais destacadas onde estão paralelas à extremidade das áreas interfasciculares. $\mathrm{O}$ interior das porçб̄es elípticas é caracterizado por grande con. centração de células mais ou menos circulares muito pequenas (Figs, 6b, 8B, 9a). Aparentemente em apenas uma das extremidades de cada área interfascicular, mais ou menos no centro das porçōes elípticas com as células quase punctiformes, nota-se a ocorrência esporádica de uma marca ovalada (de 0,2 a $0,4 \mathrm{~mm}$ de comprimento), orientada longitudinalmente ao caule, ou a presença de uma marca mais ou menos circular de tamanho semelhante, quase na extremidade de cada área interfascicular, ou ainda, ambas as marcas podem estar representadas.

Discussão - Os fósseis considerados como Paracalamites sp. 1 são interpretados como moldes internos da cavidade da medula, principalmente, pela presença das áreas fasciculares com suas nitidas recombinaçð̄es na regiâo dos nós. O comprimento bastante pequeno dos entrenós e a largura exposta relativamente grande dos caules sugerem que se trata de porções mais ou menos basais de caules. Apesar do tamanho pe. queno dos fragmentos analisados, percebe-se que os caules aparentemente sâo retos, provavelmente descartando a possibilidade de que sejam raízes ("racines", BOUREAU, 1964).

As áreas interfasciculares, provavelmente, correspondem aos raios medulares (Fig. 1), como em Calamites (BOUREAU, 1964). $O$ padrão celular do parênquima destes raios medulares e os feixes vasculares do xilema (áreas fasciculares) apresentam-se similarmente aos cortes tangenciais de cauies mineralizados do gênero Arthropitys (RENAULT, 1895, 1896; BOUREAU, 1964). O aspecto imbricado das áreas interfasciculares sobre as áreas fasciculares pode ser interpretado como resultante do colapsamento do caule devido à compactação com os raios medulares e o xilema não perfeitamente ortogonais ao plano de estratificação.

Segundo BOUREAU (1964), em Calamites o número de feixes é máximo no ponto de ligaçāo do caule à sua raiz. GORDON-GRAY et al. (1976), referindo-se a caules de Equiseta. les do Permiano Superior da África, também mencionaram que ocasionalmente dois feixes vasculares se tornam confluentes de um entrenó para o outro, reduzindo o seu número. Contudo, conforme o exemplar GP/3T $1653 \mathrm{a} / \mathrm{b}$ (Figs. $6 a, b)$, a diminuiçāo do número de áreas fasciculares nāo ocorre obrigatoriamente da base para o ápice do caule, podendo haver variaçōes em ambos os sentidos, numa mesma região nodal.

Figuras 6-9 - Moldes da cavidade da medula de Paracalamites sp. 1; afioramento AF/GP 172; escala $=4 \mathrm{~mm}$, exceto nas Figuras $8 \mathrm{~b}$ e $8 \mathrm{c}$, onde escaia $=1 \mathrm{~mm}$. 6a) espécime GP/3T 1653a; 6b) detalhe de regiäo nodal com alteraçăo do número de áreas fasciculares e interfasciculares de um entrenó para o outro. 7) exemplar com entrenós muito curtos; GP/3T 1660.8a) espécime GP/3T 1659; 8b) detalhe da extremidade de uma área interfascicular próximo ao nó; $8 \mathrm{cl}$ idem, à maior distáncia do nó. 9) espécime GP/3T 1655:9a) detalhe da regifólo nodal; 9b) aspecto geral. Figura 10 - Paracalamites aff. P. sp. 1, espécime GP/3T 1664a/b; afloramento AF/GP 177; 10a) prováveis "canais infranodais" nas áreas interfasciculares; escala $=4 \mathrm{~mm} ; 10 \mathrm{~b}$ ) detalhe de uma área interfascicular; escala $=1 \mathrm{~mm}$. 
Portanto, não é possivel orientar os caules analisados com base apenas na alteração do número de áreas fasciculares.

As pequenas marcas longitudinalmente alongadas, contidas nas porçðes elípticas das extremidades das áreas interfasciculares, poderiam equivaler a estruturas similares aos canais infranodais de Williamson descritas para Calamites em BOUREAU (1964). Entre tanto, a existência destas marcas geralmente é discutivel devido à má preservação e, em alguns exemplares, tais feiçőes parecem estar presentes em ambas as extremidades. Desta maneira, estas características também náo podem auxiliar efetivamente na orientação dos caules.

Os caules dos exemplares considerados como Paracalamites sp.1, por apresentarem entrenós provavelmente muito mais curtos que a sua largura, segundo a classificação dos caules gondvânicos sugerida por RIGBY (1966), onde este caráter é valorizado, corresponderiam a Paracalamites levis. Porém, há diversas diferenças, como o menor relevo entre as áreas fasciculares e as interfasciculares, a densidade de áreas muito mais baixa, e nó mais marcado, a linha nodal muito estreita, as extremidades das áreas interfasciculares não pontiagudas, a preservação do padrāo celular, a ocorrência de estruturas interpretadas como possiveis canais infra-nodais. e a manutenção da largura dos moldes da cavidade da medula nas regióes nodais para as porçōes médias dos entrenós.

Paracalamites sp.1 assemelha-se aos "cau. les com feições internas" descritos por GORDON-GRAY et al. (1976) quanto à disposição das áreas fasciculares na região nodal (mesmo nos casos de variaçáo do número de áreas) $\mathrm{e}$ quanto às dimensőes $\mathrm{e}$ às proporçő́es gerais. Diferencia-se pelo aspecto menos deformado, pela linha nodal mais estreita, pela preservaçăo de células nas áreas interfasciculares e pela presença de outros detalhes como os possíveis canais infra-nodais.

\section{Paracalamites aff. $P$. sp. 1}

Figs. 10a,b

Material estudado e procedência - $\mathrm{AF} /$ GP 177 - GP/3T 1662aA, bB, b/cC, 1663a/bA. $1664 \mathrm{a} / \mathrm{b}, 1668$.

Descriçāo - Os moldes (e as respectivas contra-impressōes) da cavidade da medula atingem mais de $66 \mathrm{~mm}$ de largura e mais de $36 \mathrm{~mm}$ de comprimento. A superfície dos fósseis, em geral, é suavemente ondulada, sem limites bem definidos entre as áreas fasciculares e as interfasciculares, sendo dificilmente calculáveis, com precisão, as relaçōes entre as suas larguras. Ao longo de uma linha transversal aos entrenós, verificou-se 3.8 a 10,5 áreas fasciculares (ou interfasciculares)/cm. Há finas estrias longitudinais em toda a superfície dos moldes, sendo observáveis células re tangulares a quadradas perfeitamente alinhadas nas áreas interfasciculares do exemplar GP/3T 1664a/b (Fig. 10). Também são reconheciveis nítidas cavidades elipticas nas impressōes de uma das extremidades das áreas interfasciculares, de comprimento aproximado igual a $1 \mathrm{~mm}$.

Discussão - Paracalamites aff. $P$. sp. 1 assemelha-se a Paracalamites sp.1 principalmente em relaçáo ao padráo celular, à linha no. dal estreita, e à superficie estriada com áreas fasciculares e interfasciculares mal definidas. Distingue-se pelas cavidades muito marcadas nas extremidades das áreas interfasciculares, possivelmente correspondentes a canais infranodais mais desenvolvidos do que em Paracalamites sp.1.

\section{Paracalamites $\mathrm{sp} 2$}

Figs. 3,11 a 21

Material estudado e procedència - AF/ GP $168-$ GP/3T 1622aE, 1678A, 1679A, 1685A; AF/GP 171 - GP/3T 1676a/bA; AF/ GP 172 - GP/3T 1686A;AF/GP $181-$ GP/ 3T $1683 \mathrm{a} / \mathrm{b}, 1684 \mathrm{a} / \mathrm{b} ;$ AF/GP $182-\mathrm{GP} / 3 \mathrm{~T}$ $1634 \mathrm{~b} / \mathrm{eC}, 1682,1688 \mathrm{c} / \mathrm{eB}, 1689 \mathrm{~b} / \mathrm{cC}$, 1690A,B; AF/GP 183 - GP 3T 1635bB; AF/ GP 185 - GP/3T 1692, 1693; AF/GP $189-$ GP/3T 1644; AF/GP 191 - GP/3T 1695a/bA; AF/GP 198 - GP/3T 1696; AF/GP 2.10 - GP/ 3T $1697 \mathrm{a} / \mathrm{b} ; \mathrm{AF} / \mathrm{GP} 220$ - GP/3T 1699A;AF/ GP 227 - GP/3T 1700ab/cA, aB, 1701; AF/ GP $249-$ GP/3T $1703 \mathrm{~A}, 1704 \mathrm{a} / \mathrm{b} ;$ AF/GP 282 - GP/3T 1705a/bA, a/bB, 1706A, 1707A;AF/ GP 307 - GP/3T 1760a/bA, 1761A; exemplares considerados como Paracalamites cf. P. sp.2: AF/GP $169-$ GP/3T 1678A; AF/GP $175-$ GP/3T 1681A; AF/GP 182 - GP/3T 1634aF, $1687,1688 \mathrm{fE} ;$ AF/GP $184-$ GP/3T 1691; AF/ GP 220 - GP/3T 1698; AF/GP $224-$ GP/3T $1755 \mathrm{a} / \mathrm{bA}, \mathrm{B} ; \mathrm{AF} / \mathrm{GP} 240-\mathrm{GP} / 3 \mathrm{~T} 1702 \mathrm{a} / \mathrm{bA}$; AF/GP 282 - GP/3T $1706 \mathrm{~B}, \mathrm{C}$; AF/GP 306 GP/3T 1759A;AF/GP 307 - GP/3T 1762A.

Descrição - Os caules articulados estão preservados como moldes (e respectivamente, como contra-impressøes dos moldes), originados provavelmente por preenchimento da cavidade da medula. Em geral, os moldes estāo completamente achatados, aparecendo como uma fina película de sedimentos (Fig.s. 18, 19a), ou mais 
raramente, mantêm a forma ainda levemente cilindrica, ou ainda, encontram-se fraturados longitudinalmente (Fig. 15a). Ocorrem retilineos (Figs. 12, 14, 15a, 17, 21a) ou frequientemente deformados (Figs. 11, 16, 18, 19). Em vários exemplares, além dos moldes mencionados, há um ou possivelmente mais niveis de impressōes (e respectivas contra-impressōes) não muito bem preservadas, separados entre si e dos moldes internos por fina película de sedimentos, certamente representando contramoldes de estruturas cilindricas concêntricas mais externas dos caules (Figs. 13, 15). Às vezes, o alinhamento entre os diversos niveis de impressōes náo é perfeito, provavelmente devido a deslocamentos relativos entre as partes cilíndricas mais resistentes dos vegetais ocorridos com a decomposição daquelas mais frágeis e por outros processos tafonómicos.

A largura dos caules varia entre 11,5 a mais de $95 \mathrm{~mm}$, com média igual a $24 \mathrm{~mm}$ (desvio padrão $=11,8 \mathrm{~mm}$ ); os entrenós geralmente estâo incompletos, com comprimentos de 13 a $65,5 \mathrm{~mm}$, podendo ultrapassar $120 \mathrm{~mm}$, aparentemente sem relação de proporcionalidade com a largura; ao longo de uma linha transversal aos entrenós, verificou-se 3,5 a 14,5 áreas fasciculares (ou interfasciculares) $/ \mathrm{cm}$, em média, 8,5 áreas $/ \mathrm{cm}$ (desvio padrāo $=2,3$ áreas $/ \mathrm{cm}$ ).

Os supostos moldes das cavidades das me. dulas apresentam três padrōes morfológicos básicos, levemente distintos entre si. Entretanto, estes padrós podem aparecer combinados e, portanto, săo preliminarmente interpretados como resultantes de variaçōes dos processos tafonómicos (vide item "Discussāo"). As características em comum entre estes tipos săo: a) áreas fasciculares e interfasciculares com superfície praticamente plana; b) presença de impressōes de células hexagonais a circulares ou quadradas arredondadas, possiveimente de paredes espessadas, concentradas ao longo das áreas interfasciculares ou em pelo menos uma faixa destas; c) áreas fasciculares representadas por estrias nāo exageradamente finas, nem em densidade muito grande; d) linhas nodais relativamente largas, geralmente pouco marcadas, retilíneas a ligeiramente sinuosas, podendo corresponder às porçōes mais largas dos entrenós daqueles caules com as maiores deformaçōes (Fig. 18); e) áreas interfasciculares nomalmente opostas de um entrenó para o seguinte, com extremidades bastante arredondadas a espatuladas (Fig. 14), ou freqüentemente alternas, com extremidades mais espatulado-acuminadas, às vezes, apresentando uma pequena marca mais ou menos circular (Fig, 16); f) áreas fasciculares aparentemente tricotomizadas na regiāo nodal e recombinadas nos entrenós adjacentes como em Paracalamites sp.1, porém com menor divergéncia entre as bandas resultantes da tricotomia e curso mais suave (Fig. 14); nos casos de áreas interfasciculares em posição alterna (Fig. 16), observada apenas uma simples dicotomia das áreas fasciculares nas passagens dos nós.

Entre os três padrôes morfológicos de moldes da cavidade da medula, o primeiro caracteriza-se por áreas fasciculares e interfasciculares praticamente sem diferença de relevo, sendo distinguiveis apenas pela presença de células bem definidas nas primeiras e de estrias nas últimas. As células da porção central das áreas interfasciculares são curtas, largas, hexagonais a quase circulares e, em direçāo às margens, passam gradual ou abruptamente a formas mais alongadas e estreitas, de paredes ainda arredondadas (largura $=0,04$ a $0,09 \mathrm{~mm}$; comprimento $=0,08$ a $0,3 \mathrm{~mm}$ ). As células náo se dispōem muito bem alinhadas na direçăo longitudinal. $O$ padrāo celular próximo aos nós nāo foi observado por problemas de preservação, porém, é constante ao menos nas partes analisadas dos entrenós. As áreas fasciculares apresentarn 6 a 8 estrias longitudinais fortes e contínuas, além de finas estrias intermediárias. A largura das áreas interfasciculares é aproximadamente igual a 1,5-2,3 vezes a largura das fasciculares.

O segundo padrão de moldes da cavidade da medula distingue-se do primeiro pela presença de um estreito sulco entre as áreas interfasciculares e as fasciculares (Fig. 17). Estes sul$\cos$ nāo foram verificados na regiāo nodal (Fig. 14). Em alguns raros casos, além dos sulcos citados, ocorrem outros subsidiários nas áreas interfasciculares, subdividindo-as em três faixas, isto é, uma central com células mais isodiamétricas e duas faixas laterais com células mais alongadas. O espécime GP/3T 1683a/b (Fig. 19) é um exemplo onde há passagem deste padrão de molde medular para o primeiro padråo descrito acima. Em algumas partes da sua superficie, as áreas fasciculares sāo separadas das interfasciculares por sulcos; em outras, ao invés de sulcos há linhas definidas cromaticamente; e ainda em outras partes, a superficie é praticamente lisa.

O terceiro padrāo de moldes da cavidade da medula caracteriza-se pelo aspecto imbricado das áreas fasciculares e interfasciculares (Figs. 20,21 ). Tal padrăo é observado, em particular, nas regiōes nodais (Fig. 20) e nas porçôes mais laterais de moldes da cavidade da medula que apresentam alguma remanescência da forma cilíndrica original, principalmente quando os caules são de pequeno porte. A largura das áreas fasciculares em relação à largura da porção 

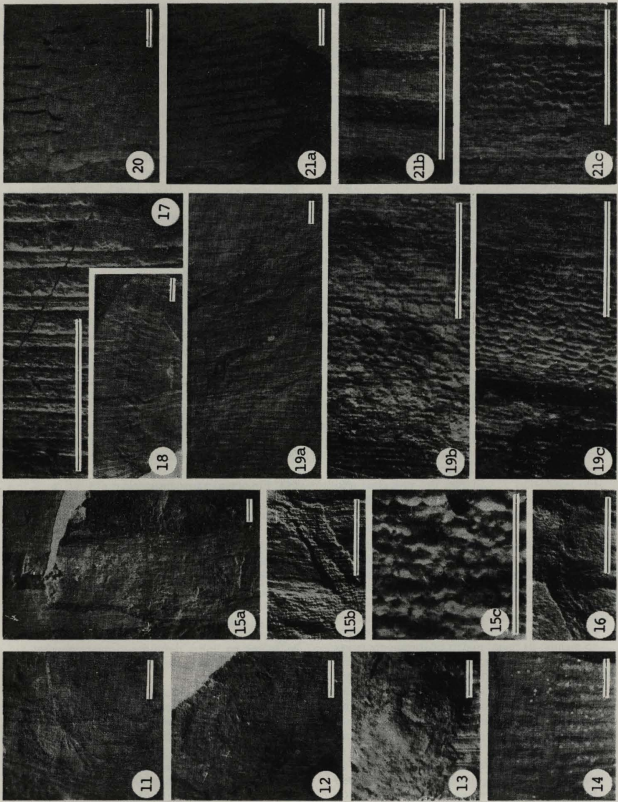
ainda exposta das áreas interfasciculares é igual a $1: 0,36-1: 1$. As áreas interfasciculares são representadas por células pentagonais a hexagonais, mais ou menos isodiamétricas a levemente alongadas (de aproximadamente 0,13 a $0,14 \mathrm{~mm}$ de diâmetro), com aspecto levemente imbricado (Fig. 21c). As áreas fasciculares normalmente apresentam 5 a 6 estrias longitudinais pouco marcadas e várias finas estrias intermediárias. As porçōes menos imbricadas podem passar longitudinalmente ao padrão com os estreitos sulcos entre as áreas fasciculares $e$ as interfasciculares, porém sem al terar substancialmente o padrāo das células.

$\mathrm{Na}$ parte exposta de alguns moldes da cavidade da medula, geralmente naqueles de padrão imbricado ou com os sulcos, podem existir uma ou duas estruturas mais ou menos cônicas, situadas quase junto às linhas nodais, respectivas à inserção de ramos na superfície externa dos caules (Figs. 11, 12, 18). Estas estruturas apresentam diâmetros entre 4,5 e $10,0 \mathrm{~mm}$ e caracterizam-se pela convergència dos vasos responsáveis pelo intercâmbio entre o caule principal e os ramos, compreendendo 6 a 18 áreas fasciculares (e áreas interfasciculares) dirigidas radialmente para um pequeno círculo central de 1,25 a $1,50 \mathrm{~mm}$ de diâmetro. Em alguns exemplares, as estruturas cônicas de menores dimensōes podem estar circundadas por uma auréola de 6,2 a $9,1 \mathrm{~mm}$ de diâmetro, constituída por finíssimas estrias concêntricas (Fig. 11).

Os contramoldes de um dos tecidos mais externos dos caules, formados por finíssimas películas sedimentares adjacentes aos moldes da cavidade da medula, estāo preservados em apenas pequenas áreas (Figs. 15a,b). Apresentam células alongadas (largura $=0,04$ a
$0,15 \mathrm{~mm}$; comprimento $=0,10$ a $0,32 \mathrm{~mm})$, alinhadas longitudinalmente, de margens sinuosas a arredondadas, com tamanho mais ou menos uniforme ao longo de uma mesma fileira, porém podendo variar de uma fileira para a outra (Fig. 15c). Verificou-se ainda a sobreposição destas impressōes por outras finíssimas películas sedimentares, aparentemente correspondentes a contramoldes de estruturas ainda mais externas, apresentando impressōes da possivel epiderme dos caules. Estão mal preservadas e seu aspecto é praticamente liso. Contramoldes ou impresső́es de estruturas e tecidos mais externos das regiōes nodais, infelizmente, nāo se encontram entre o material coletado. Há somente um exemplar (GP/3T 1689b/cC, Fig. 13), onde resta um provável contramolde de cicatriz de inserção de ramo constituído por dois anéis concêntricos, convexos e ligeiramente cônicos, situado sobre o molde da cavidade da medula.

Discussāo - Em Paracalamites sp.2, os moldes com as impressōes de áreas fasciculares e interfasciculares, provavelmente correspondentes aos moldes medulares, podern ser interpretados como em Paracalamites sp. 1. As áreas interfasciculares representariam os raios medulares $\mathrm{e}$ as áreas fasciculares equivaleriam ao xilema (Fig. 1), assemelhando-se, quanto ao padrẩo geral, a Arthropitys (RENAULT, 1895, 1896; BOUREAU, 1964).

As diferenças entre os três padrōes de moldes da cavidade da medula observados, conforme mencionado anteriormente, sāo interpretadas como resultantes dos fenômenos tafonômicos, em particular, das pressōes e das tensōes sofridas pelos caules durante a compactação dos depósitos sedimentares. Os padrōes variam tam-

Figuras 11-21 - Paracalamites sp.2; escala - 4mm, exceto nas Figuras 15c, 19b, 19c e 21c, onde escala = $1 \mathrm{~mm}$. Fig. 11 - Estrutura respectiva à inserçäo de ramo no molde da cavidade da medula; especime GP/3T 1692: afloramento AF/GP 185. Fig. 12 - Idem; especime GP/3T 1700a/bA; afloramento AF/GP 227. Fig. 13 - Idem, porém num nivel mais externo do caule, recobrindo parcialmente o moide da cavidade da medula; espécime GP/3T 1689bC; afloramento AF/GP 182. Fig. 14 - Regiâo nodal em molde de cavidade da medula; espécime GP/3T 1685A; afloramento AF/GP 168. Fig. 15 - Espécime GP/3T 1707A, afloramento AF/GP 282:159) molde da cavidade da medula parcialmente recoberto por fina película de sedimentos com a contra-impressåo da provável superfície interna do cbrtex, 15b) detalhe dos dois niveis (luz incidente a partir do canto inferior direito); 15c) detalhe do padrăo celular. Fig. 16 - Regiăo nodal do molde da cavidade da medula com prováveis "canais infranodais" nas áreas interfasciculares, espécime GP/3T 1682; afloramento AF/GP 182. Fig. 17 - Moide da cavidade da medula com sulcos entre as áreas interfasciculares e as fasciculares; espécime GP/3T $1699 \mathrm{~A}$; afloramento AF/GP 220. Fig. 18 Regiáo nodal com duas estruturas respectivas à inserção de ramos om molde da cavidade da medula de caule deformado e representado por fina película de sedimentos compactada (nivel inferior correspondendo à contra-impressfo do molde da cavidade da medula); especime GP/3T 1686A; afloramento AF/GP 172. Fig, 19 - Espécime GP/3T 1683a; afloramento AF/GP 181:19al molde da cavidade da medula; 19b) detalhe do padrắo celular na superfície do molde com a área interfascicular na regiăo central da figura; $19 \mathrm{cl}$ Idem na superfície da contra-impress5̃o do molde; observar a separaç̧o mais nítidada ârea interfascicular das áreasfasciculares em $c$ do que em $b$; no canto infe.

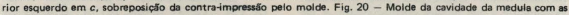
áreas fasciculares e interfasciculares completamente imbricadas, particularmente na regiẫo nodal; especime GP/3T 1678A; afloramento AF/GP 168. Fig. 21 - Espécime GP/3T 1622aE; afloramento AF/GP 168; moide da cavidade da medula com as áreas interfasciculares e fasciculares variavelmente imbricadas; 21 a) molde e contra-impresş̂́ do molde no canto inferior esquerdo da figura; $21 \mathrm{~b}$ ) detalhe das áreas fasciculares e interfasciculares; $21 \mathrm{c}$ ) detalhe do padrāo celular. 
bém com o diâmetro dos caules e a posição relativa das porçōes analisadas. Provavelmente, quando os raios medulares se fossilizaram ortogonalmente ao plano de estratificação, formaram-se os moldes dos padrōes com superfície lisa (Fig. 19b) ou com os sulcos entre as áreas interfasciculares e as fasciculares (Fig. 17). Nos casos em que deformaçōes e rupturas provocaram a disposição mais ou menos inclinada dos raios medulares e dos raios lenhosos em relaçăo ao vetor pressฐ̃o litostática, originaram-se os moldes do padrão imbricado. Tal imbricamento permitiu a exposiçåo de uma área maior da superfície dos raios lenhosos e possivelmente de parte de uma de suas margens laterais, além da apreensão de sedimentos entre a outra margem e a porçāo oculta das áreas interfasciculares (Fig. 20).

As feições circulares observadas numa das extremidades das áreas interfasciculares (Fig. 16) podem equivaler a canais infranodais (BOUREAU, 1964). As estruturas cônicas com yasos em convergência nos moldes da cavidade da medula (Figs. 11, 12), as quais são respectivas a inserção de ramos, assemelham-se muito a algumas em Calamites na Europa figuradas em BOUREAU (1964), como por exemplo, em Calamites (Diplocalamites) paleaceus Stur, 1887. Conforme os trabalhos consultados, nāo há registro destas marcas e nem dos possiveis canais infra-nodais para os caules de esfenófitas do Gondvana. RIGBY (1969) apresentou figuras de estruturas por ele interpretadas como diafragmas nodais (Est. 1, figs. 2,3); no entanto, tais feiçōes devern corresponder, com maior probabilidade, a estruturas cônicas respectivas a inserção de ramos. Ainda digno de nota é o fato de ser relativamente comum a ocorrência de áreas interfasciculares em posiçâo alterna na passagem dos nós de Paracalamites sp.2, mesmo quando não é evidente o acréscimo ou a supressâo de uma área interfascicular de um entrenó para o outro. Em relação aos outros caules de esfenófitas gondvânicos, este caráter sempre é citado como sendo de exceção, explicável unicamente pela variação numérica e acomodaçāo das estruturas.

As duas finas películas sedimentares que aparecem sobrepostas ao molde da cavidade da medula de alguns exemplares săo contramoldes de estruturas cilindricas mais externas dos caules. Contudo, não apresentam características suficientemente diagnósticas para determinar exatamente a que tecidos correspondem. A película mais interna (Fig. 15) poderia representar o preenchimento do espaço deixado pelo floema, cuja degradação deve ter sido mais rápida que o restante do caule. Desta forma, a impres- são com as células relativamente grandes e homogêneas nesta película equivaleria à superfície do limite interno do córtex. A superfície mais ou menos lisa da outra película, ainda mais externa (não visivel na Fig. 15), poderia corresponder à contra-impressão da epiderme

Paracalamites sp. 2 deve ser da mesma natureza que outros caules de esfenófitas da Formação Rio do Rasto figurados, como Phyllotheca? sp. em MENDES (1954, Est. 1, figs. 6, 7), Paracalamites sp. em BORTOLUZZI (1975) e Paracalamites australis descrito por CAZZU. LO-KLEPZIG (1978) e CAZZULO-KLEPZIG \& CORREIA (1981). Não é adequado considerar estes caules como Paracalamites australis pelas regiб̄es nodais mais marcadas, regulares e largas, pelas extremidades mais arredondadas das áreas interfasciculares, apresentando possiveis canais infra-nodais, pela presença de estruturas cônicas respectivas à inserçāo de ramos e pela diferença dos parâmetros quantitativos. Adicionalmente, Paracalamites sp. 2 apresenta preservação de impressōes de células da superfície da cavidade da medula e de outros tecidos mais externos e ondeamento menos proeminente da superficie do molde medular (refletindo a forma mais plana das áreas fasciculares e interfasciculares).

Paracalamites sp. 2 distingue-se de Paracalamites sp. 1 pelos entrenós relativamente mais longos e mais deformados (possivelmente indicando maior fragilidade), pela densidade normalmente maior de áreas interfasciculares e fasciculares, pela ocorrência de células menos homogêneas e menos alinhadas nas áreas interfasciculares, não the conferindo um aspecto estriado, pela linha nodal mais larga e irregular e pela forma geralmente mais arredondada das extremidades das áreas interfasciculares, ambos os últimos fatores contribuindo para que as bandas da tricotomia das áreas fasciculares ocorram encurvad as mais suavemente e menos divergentes.

As linhas nodais de Paracalamites sp. 2 assemelham-se àquelas dos caules descritos por GORDON-GRAY et al. (1976), porém há algumas diferenças para o restante das características, aproximadamente as mesmas já citadas em relação a Paracalamites sp.1.

\section{Paracalamites sp. 3}

Figs. 4, 22, 23

Material estudado e procedência - AF/ GP $174-$ GP/3T 1670A, 1673A, 1674;AF/GP 210 - GP/3T $1675 \mathrm{a} / \mathrm{bA}$; exemplares considerados como Paracalamites cf. $P$. sp. $3:$ AF/GP 174 - GP/3T 1671A,B,C, 1672; AF/GP 183 - GP/ 3T 1637aD (Fig. 24). 
Descrição - Paracalamites sp. 3 é repre. sentado por moldes e contra-impressōes de moldes da cavidade da medula de caules articulados, com entrenós de 9.5 a mais de $2.5 \mathrm{~mm}$ de largura e ultrapassando $54 \mathrm{~mm}$ de comprimento. O exemplar GP/3T 1637aD, considerado como Paracalamites cf. $P$. sp.3, apresenta largura igual a $15 \mathrm{~mm}$ e comprimento de entrenó igual a $42 \mathrm{~mm}$.

Tratando-se de formas susceptiveis a diversas interpretaçбós, aqui é apresentada somente uma mera descriçāo das estruturas; ș̃o utilizados os termos "costela" e "sulco" apenas como feiçōes morfológicas e nāo no sentido de "areas interfasciculares" $\mathrm{e}$ "ăreas fasciculares".

As linhas nodais sẩo estreitas e retilineas. O exemplar GP/3T 1673A (Fig. 22a) exibe a impressão da linha nodal em depressão. As costelas ocorrem em posição geralmente sub-oposta de um entrenó para o outro, com extremidades de forma aguda e com pequeno imbricamento (Fig. 22b). Esporadicamente existem pequenas proeminéncias alongadas e mal preservadas ligando as extremidades das costelas de dois entrenós contiguos. Nas regiỏes mais salientes das costelas, passando para os seus flancos mais suaves, e ainda, nas regióes mais baixas adjacentes às costelas, há células mais ou menos retangulares, não muito alongadas (largura $=0,05$ a $0,06 \mathrm{~mm}$, comprimento $=0,10 \mathrm{a} 0,13 \mathrm{~mm}) \mathrm{de}$ margens um pouco mais arredondadas nas porções mais altas e tendendo a retilineas nas mais baixas (Fig. 22b). À pequena distäncia da linha nodal (a mais ou menos 1,5 a 2,5 mm), as costelas aparecem mais largas, quase planas, separadas por sulcos estreitos e rasos. A distância um pouco maior (a cerca de $3 \mathrm{~mm}$ da linha nodal), as costelas normalmente dividem-se em duas partes ligeiramente desiguais (relação entre as larguras = $1: 1,3$ a $1: 1,6)$, apresentando superfícies planas e arredondadas nas arestas (Fig. $22 \mathrm{c}$ ). Todas estas subdivisōes estāo limitadas entre si por sulcos mais ou menos profundos, estreitos, com finas estrias. Nas subdivisőes mais largas, geralmente melhor preservadas, ocorrem 4 ou 5 fileiras de células retangulares e alinhadas longitudinalmente (larguras $=0,05$ a $0,06 \mathrm{~mm}$, comprimento $=0,2 \mathrm{~mm})(\mathrm{Fig}, 22 \mathrm{c})$. Aparentemente, existem células também nas subdivisőes mais estreitas. No exemplar GP/3T $1675 \mathrm{a} / \mathrm{bA}$ (Fig. 23), a divisão das costelas naึo é tão evidente, porém o padrāo celular parece ser o mesmo. Outros exemplares analisados possuem caracteristicas mais ou menos equivalentes, podendo uma mesma costela estar subdividida ou nāo e apresentar imbricamento variável. Considerando as costelas indivisas ou os pares de subdivisôes das costelas, ao longo de uma linha transversal aos entrenós, verificou-se 16,7 a 22,5 costelas $/ \mathrm{cm}$.

O exemplar GP/3T 1675a/bA (Fig. 23). embora mal preservado na regiäo nodal, permite a observação de duas marcas levemente cônicas respectivas à inserção de ramos; uma das marcas está na porção superior do molde e aparece em relevo e a outra, mais fraca, em depressāo, quase coincidente com a primeira, localiza-se na superfície oposta do caule, sendo reconhecivel devido à espessura muito pequena do molde da cavidade da medula. As marcas apre. sentam forma circular com 1,5mm de diâmetro, havendo cerca de 8 prováveis áreas fasciculares dirigidas para um ponto excêntrico.

$\mathrm{O}$ exemplar GP/3T 1637aD (Fig. 24). considerado como Paracalamites cf. $P$. sp. 3 , é caracterizado por costelas constituindo simples ondulaçб̄es, nåo bem preservadas; verificou-se cerca de 23,9 costelas/cm ao longo de uma linha transversal ao caule.

Discussǟo - Vários aspectos distinguem Paracalamites sp. 3 dos demais caules aqui descritos, principalmente o padrāo celular, a largura das células relativamente grande em comparaçāo à largura pequena das costelas, a presença de células igualmente bastante grandes nas áreas deprimidas perto dos nós, a alta densidade de costelas, suas extremidades mais ou menos agudas e imbricadas, e as evidentes variaçōes de suas características na região nodal. O caráter variável das costelas, nđ̄o observado nas outras espécies descritas, poderia ser parcialmente explicado pelas deformações sofridas pelos caules durante a compactação. As células relativamente grandes tanto nas porções elevadas como nas deprimidas da regiāo nodal e a auséncia de estrias sugerem que apenas as superfícies correspondentes aos raios medulares aparecem visiveis nesta parte do molde da cavidade da medula. Supōe-se que, na regiāo nodal, um forte imbricamento dos raios medulares e dos raios lenhosos tenha ocultado quase completamente estes últimos. À maior distância dos nós, onde os caules, em geral, reagem menos à compactação dos sedimentos, nāo teria ocorrido tal imbricamento. A subdivisão mais larga de cada costela poderia corresponder à área interfascicular e a outra subdivisão, à área fascicular. Os sulcos entre as áreas fasciculares e interfasciculares em Paracalamites sp. 3 podem ser equivalentes aos sulcos verificados em Paracalamites sp.2. Os caules de Paracalamites sp. 3 talvez correspondam a ramos menores ou a partes mais distais de caules do tipo Paracalamites $\mathrm{sp} .2$, e as diferenças observadas poderiam ser resultantes dos graus distintos de resistência à 

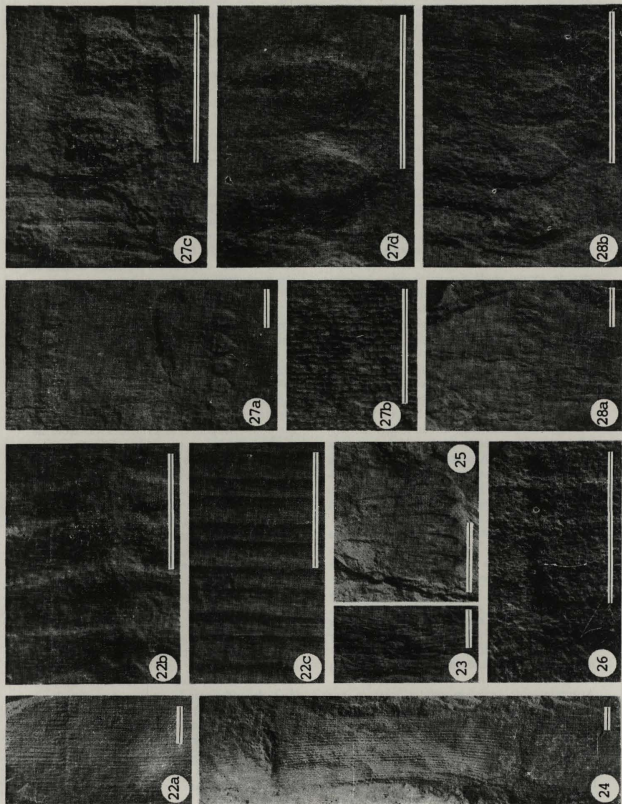
decomposição e à compactação. Contudo, o padrão celular contrastante nžo corrobora tal hipótese.

O exemplar GP/3T 1637aD (Fig. 24), considerado como Paracalamites of. $P$. sp. 3 , assemelha-se, talvez pelo estado de preservação precário, aos exemplares normalmente considerados como $P$. australis e poderia corresponder a caule de Schizoneura gondwanensis, encontrado em associação no mesmo afloramento (ROHN \& RÖSLER, 1986).

\section{Paracalamites sp. 4 \\ Figs. $5,25,27,28$}

Material estudado e procedencia - AF/ GP 197 RR/PR - GP/3T 1665B, 1666A, $1669 \mathrm{dC}$; exemplares considerados como Paracalamites cf. $P$. sp.4:AF/GP 197 - GP/3T 1666B, 1667bD (Fig. 26), 1669bD.

Descriçáo - Os caules são articulados e representados por impressōes da superfície supostamente externa do caule; somente num exemplar (GP/3T 1665B, Fig. 27) há resquícios de uma fina película sobreposta à impressão da superfície externa, onde se verifica uma provável contra-impressáo do molde da cavidade da medula. Os exemplares considerados como Paracalamites of. $P$. sp. 4 apresentam características equivalentes à superfície desta película $\mathrm{e}$ também devem corresponder a moldes e a con. tra-impressōes dos moldes medulares.

O exemplar GP/3T 1665B apresenta dois entrenós completos preservados, de $19,7 \mathrm{~mm}$ de comprimento e aproximadamente $18,7 \mathrm{~mm}$ de largura; o exemplar GP/3T 1666A exibe largura superior a $25 \mathrm{~mm}$.

As impressōes das supostas superfícies externas caracterizam-se por extensas áreas homogêneas com células quadradas, retangulares a ligeiramente hexagonais alongadas, alinhadas longitudinalmente, de largura mais ou menos uniforme (largura $=0,05$ a $0,07 \mathrm{~mm}$, comprimento $=0,06$ a $0,14 \mathrm{~mm})$ (Fig. 27b). Nestas impressōes ocorrem regiōes nodais bem destacadas, representadas por 6 a 9 marcas deprimidas, cordiformes, gutiformes a elípticas, lateralmente contíguas, de 2 a $3 \mathrm{~mm}$ de comprimento por 1,1 a $2,2 \mathrm{~mm}$ de largura, provavelmente correspondentes a moldes de bases foliares (Figs. 5a, 27). No exemplar GP/3T $1669 \mathrm{dD}$ (Fig. 28), as marcas não estão totalmente cırcunscritas. Verificou-se 4,5 a 5,8 marcas $/ \mathrm{cm}$ em cada linha nodal. Entre o centro e a extremidade mais larga das marcas observa-se uma feiçāo circular a elíptica, ainda mais deprimida, de aproximadamente $0,5 \mathrm{~mm}$ de comprimento máximo. E na extremidade mais larga, há outra estrutura, porém bem protuberante, circular a triangular aguda, de 0,5 a $0,8 \mathrm{~mm}$ de comprimento. Cada uma destas estruturas freqüentemente corresponde ao ponto de origem de uma linha longitudinal saliente, estendida por um trecho igual a $1 / 4$ ou mais do comprimento do entrenó. Nos casos da presença destas linhas, ocorrem ainda outras linhas longitudinais, intermediárias e paralelas, de igual comprimento e indistintas das primeiras, partindo dos limites laterais das supostas cicatrizes foliares (Fig. 27d).

No exemplar GP/3T 1669dC (Fig. 25), tem-se a contra-impressāo do molde externo de dois entrenós incompletos. Num dos dois, estão presentes lâminas alongadas, longitudinais, planas, aproximadamente paralelas (largura $=$ $1,2 \mathrm{~mm}$, comprimento superior a $9 \mathrm{~mm})$, lateralmente contíguas, separadas por estreitos sul$\cos$, que apresentam, na região nodal, extremidades de forma ogival, exatamente equivalentes a cada uma das marcas atribuídas a bases foliares nos demais exemplares com a exposiçăo da superfície externa. Transparecem ainda as estruturas internas destas marcas. Na porção preservada do outro entrenó, a superfície aparece lisa, sem as lâminas. Este conjunto de ca-

Figuras 22 e 23 - Moldes da cavidade da meduia de Paracalamites sp.3. 22al Espécime GP/3T 1673A; afio. ramento AF/GP 174; escala - 4mm; 22b) detalhe da regiäo nodal; escala $=1 \mathrm{~mm} ; 22 \mathrm{c}$ ) detalhe das áreas fasciculares e interfasciculares à maior distância do no; escala $=1 \mathrm{~mm}$. Fig. 23 - Duas estruturas respectivas à inserção de ramos, uma na superfície do molde e a outra decalcada atravts da finíssima película do molde; especime GP/3T $1675 \mathrm{aA}$; afloramento AF/GP 210; escala $=4 \mathrm{~m}$.

Figura 24 - Molde da cavidade da medula de Paracalamites cf. P. sp.3; espécime GP/3T 1637aD; afloramento AF/GP 183, escala $=4 \mathrm{~mm}$.

Figuras 25, 27 a 28 - Paracalamites sp.4, afloramento AF/GP 197; escala $=4 \mathrm{~mm}$, exceto na figura $27 \mathrm{~b}$, onde escala - $1 \mathrm{~mm}$. Fig. 25 - Contra-impressåo do molde externo do caule e provável contramolde da bainha foliar especime GP/3T 1669dC. Fig. 27 - Espécime GP/3T 1665B; 27a) impressāo da superfície externa do caule parcialmente sobreposta (à esquerda) por fina película sedimentar com a contra-impressāo da superfície da cavidade da medula: 27b) detalhe do padrão celular da superficie externa; $27 \mathrm{c}$, d) detalhes da regiāo nodal com moldes de bases foliares. Fig. 28 - Espécime GP/3T 1666A: 28a) impressð̌o da superfície externa; 28b) detalhe da regiăo nodal.

Figura 26 - Contra-impressão do molde da cavidade da medula de Paracalamites cf. P. sp.4; espécime GP/3T 1667bD; afloramento AF/GP 197; escala = 4mm 
racterísticas permite deduzir que as lâminas de. vem corresponder a contramoldes de folhas soldadas entre si, ao menos basalmente, constituindo uma bainha foliar, provavelmente com pequeno ângulo de divergéncia em relação ao caule.

Nos moldes da superfície externa dos demais exemplares descritos acima, com padrão celular homogêneo ao longo dos entrenós (Figs. $5,27,28)$, as linhas longitudinais protuberantes, que partem da regiåo nodal, podem representar o decalque das feiçōes mais robustas de uma bainha foliar (alternadamente das nervu. ras medianas e das linhas de comissuras) através de uma película sedimentar pouco espessa separando a impressão da superfície externa do cau. le daquela da bainha foliar, situada num nivel ainda mais exterior. Estas interpretaçōes e. principalmente, a identificação de prováveis folhas no exemplar GP/3T $1669 \mathrm{dC}$, permitem orientar os caules conforme as figuras apresentadas (Figs. 5a, 25, 27, 28).

A provável contra-impressāo do molde medular do exemplar GP/3T 1665B (canto superior esquerdo e lado esquerdo das Figuras $27 \mathrm{a}, \mathrm{c})$, supostamente apresenta áreas fasciculares em relevo bem destacadas em relação às áreas interfasciculares. Sua densidade é de 12,8 áreas $/ \mathrm{cm}$ e a razão entre as larguras das áreas fasciculares e as das interfasciculares é igual a $1: 3,8$. Observam-se estrias longitudinais em toda a superfície, com espaçamento aproximadamente igual a 0,05 a $0,07 \mathrm{~mm}$. Esta possivel contra-impressão do molde interno, apesar de situada ao nível da regiāo nodal da superfície externa, não apresenta características nodais. Este fato poderia ter razões tafonômicas como um pequeno deslocamento longitudinal entre os cilindros mais resistentes do vegetal, facilitado pela decomposição dos tecidos intermediários mais frágeis. Os outros exemplares de prováveis moldes medulares do mesmo afloramento, considerados como Paracalamites cf. $P$. sp.4, também apresentam áreas fasciculares e interfasciculares nitidamente separadas, com diferença de relevo significativa ou, em outros casos, estas áreas såo menos destacadas e constituem somente leves ondulaçōes nas superfícies dos moldes (Fig. 26). As áreas interfasciculares normalmente ostentam apenas estrias ou mesmo aparecem lisas. O exemplar GP/3T $1666 \mathrm{~B}$, ainda que mal preservado, é uma exceçāo por exibir, em cada área interfascicular, 19 ou 20 fileiras de células alinhadas longitudinalmente, muito alongadas, de margens ligeiramente smuosas (largura $=0,03$ a $0,04 \mathrm{~mm}$, comprimento 0,15 a $0,20 \mathrm{~mm}$ ). Tal exemplar possui áreas fasciculares com 7 a 10 estrias, separadas entre si numa distância mais ou menos igual à largura das células das áreas interfasciculares. A contraimpressão de molde medular no espécime GP/ 3T 1667 bD (Figs. Sb, 26) apresenta uma região nodal caracterizada por um alargamento acentuado das áreas fasciculares, formando um padrão de figuras mais ou menos losangulares coincidentes com protuberâncias arredondadas e acentuadas na "linha" nodal; porém, praticamente não são visiveis as trocas de vasos entre as áreas fasciculares adjacentes.

Discussão - A designação Paracalamites não seria adequada para as impressőes das superfícies externas dos caules analisados porque a diagnose do gênero se refere às características dos moldes da cavidade da medula (ZALESS. KY, 1927). No entanto, a ocorréncia de um exemplar (GP/3T 1665B, Figs. 27a, c), onde uma película de sedimentos com a contra-im. pressāo do suposto molde medular sobrepōe a impressão da provável superfície externa do caule, permite extrapolar a aplicação do nome para os outros exemplares do mesmo aflora. mento. Esta decisão também visa não complicar desnecessariamente o quadro bioestratigráfico a ser apresentado em trabalhos futuros.

RIGBY (1966) descreveu supostas superfícies externas de Paracalamites australis, as quais apresentariam caneluras e saliências similares àquelas dos moldes da cavidade da medula, diferenciando-se somente por serem menos marcadas. Entretanto, num trabalho posterior, RIGBY (1969) refutou tal interpretaçāo e os exemplares anteriormente referidos foram considerados como moldes da cavidade da medula.

Conforme a literatura consultada sobre as esfenófitas do Gondvana, as impressōes das superficies externas de Paracalamites sp. 4 assemelham-se apenas às superficies externas dos caules descritos por GORDON-GRAY et al. (1976). Alguns dos caules de maior porte da África do Sul, desprovidos de folhas e designados como "stems thought to exhibit external features", têm parte de sua superficie lisa, com impressão dos contornos das células; mostram nós caracterizados por linhas horizontais e paralelas, próximas entre si e adjacentes a cicatrizes ovais, interpretadas como correspondentes às áreas de inserça de folhas verticiladas; marcas protuberantes excêntricas no interior das cicatrizes representariam a posiçăo de um feixe vascular; sulcos longitudinais pronunciados, cada qual margeado por duas fracas saliências, separam as cicatrizes foliares, estendendo-se mais ou menos até a metade de cada entrenó. GORDONGRAY et al. (1976) concluíram que estes sul$\cos \mathrm{e}$ as cicatrizes dos feixes vasculares prova. 
velmente permitem orientar os caules sem folhas com a seguinte argumentação: as bainhas foliares, preservadas em outros caules, de menor porte, deveriam proteger a base meristemática do entrenó acima do nó (como observado atual. mente em Equisetum sp.; nota dos autores), onde, portanto, deveriam estar localizados os sulcos longitudinais mais pronunciados; as marcas de inserção dos feixes vasculares deveriam estar posicionados distalmente nas cicatrizes foliares. Desta forma, a parte superior dos entrenós seria lisa.

As estruturas nas superfícies externas em Paracalamites sp.4, embora diferentes daquelas descritas em GORDON-GRAY et al. (1976) em relação à forma e ao tamanho, apresentam padrão geral de organização muito semelhante. Contudo, as linhas longitudinais originadas na região nodal, conforme comentado anteriormente, podem não ser feições da própria superfície externa dos caules e sim, devem representar o decalque, através de uma fina película sedimentar, das linhas de comissuras e das nervuras medianas de uma bainha foliar. Isso é corroborado pelo exemplar GP/3T 1669dC (Fig. 25 ), onde parecem estar presentes as contraimpressōes dos moldes das próprias folhas. De qualquer modo, a orientação dos caules é a mesma, tanto para as interpretaçōes apresentadas por GORDON-GRAY et al. (1976), como em relação aos argumentos aqui apresentados. A probabilidade maior de que as áreas expostas das amostras sejam resultado da partição da rocha sedimentar segundo os planos com as impressōes dos caules - por geralmente representarem planos de fraqueza mais extensos e homogêneos - $\mathrm{e}$ a possibilidade aventada por GORDON-GRAY et al. (1976) de que as folhas mais velhas seriam destacadas do vegetal durante o seu desenvolvimento ontogenético, explicariam a rara ocorrencia de folhas visivelmente atadas a caules. Infelizmente, a preciosa área exposta da bainha foliar do exemplar GP/3T 1669 não é suficientemente extensa e diagnóstica para permitir efetivas comparaçōes com outras espécies de caules com folhas. Tal motivo tornou preferível considerar, preliminarmente, este exemplar como Paracalamites sp.4.

As folhas e os caules com suas marcas características de bases foliares distinguem-se seguramente daquelas esfenofitas anteriormente conhecidas para a Formaçāo Rio do Rasto: Schizoneura gondwanensis, Sphenophyllum paranaense, Sphenophyllum $\mathrm{cf}$. S. thonii (e ainda, Dichophyllites sp., segundo BORTOLUZZI, 1975). GORDON-GRAY et al. (1976) consideraram que os seus caules apresentam maior afinidade às Equisetaceae do que às Calamitaceae, podendo haver alguma relação com Equisetites. De fato, os caules da África do Sul e os aqui analisados distinguem-se das raras superfícies externas mencionadas ou figuradas de Calamites e de Paracalamites (BOUREAU, 1964), sendo discutivel a inclusāo de "Paracalamites" sp.4 na familia Calamitaceae.

Quanto aos prováveis moldes da cavidade da medula, valem as observaçōes já apresentadas para as outras espécies anteriormente descritas neste trabalho. Os exemplares considerados como Paracalamites cf. $P$. sp. 4 são semelhantes a Paracalamites sp.1 quanto à superfície totalmente estriada, distinguindo-se principalmente pelas características dos nós (GP/3T $1667 \mathrm{bD}$, Fig. 26) e pelo contorno das células (GP/3T 1666B). O comportamento e a forma das áreas fasciculares e interfasciculares lembram Phyllotheca indica Bunbury descrita em PANT \& KIDWAI (1968). Contudo, tal comparação não pode ser extrapolada para os caules com as feiçōes externas, considerados como Paracalamites sp.4, pela já insólita relaçāo entre estes exemplares e aqueles com as feiçőes internas. Alguns dos outros problemas na comparação com Phyllotheca indica são o desconhecimento da superfície externa desta espécie e, principalmente, o fato da sua diagnose estar fundamentada nas características dos órgăos foliares.

\section{AGRADECIMENTOS}

Os autores agradecem à S. Czajkowski, ao V. Czajkowski e à E. Mendonça pela importante colaboração nos trabalhos de campo, ao J. de S. Taddeo (DMGA-IPT) e ao Dr. H.D. Schorscher (DMP-IG-USP) por terem facilitado a utilização de lupas fotográficas das respectivas instituiçōes, ao A.G. Rohn pelas sugestōes e colaboração nos serviços de fotografia, à Dra. D. Mussa pela providência de cópias de valiosos trabalhos pertinentes ao assunto, e particularmente ao Dr. T.R. Fairchild pela correçāo do "abstract" e pela revisāo crítica do trabalho. 


\section{REFERENCLIAS BIBLIOGRĀFICAS}

BORTOLUZZI, C.A. (1975) Étude de quelques empreintes de la flore gondwaniénne du Brésil. $95^{\text {eme }}$ Congr. Natl. Soc. Savantes, Reims, 1970, Comptes Rendus, Bibliothèque Nationale, p. 171-187.

BOUREAU, E. (1964) Traité de paléobotanique. Tome 3 - Sphenophyta, Noeggerathiophyta. Paris, Masson et Cie., $544 \mathrm{p}$.

CAZZULO-KLEPZIG, M. (1978) Estudo da tafofórula do Membro Morro Pelado na sua localidade-tipo. Pesquisas. $11: 225-303$.

CAZZULO-KLEPZIG, M. \& CORREIA, N. dos R. (1981) Contribuição ao estudo da tafoflora permiana do Membro Serrinha na Serra do Cadeado, Estado do Paraná, Brasil. II Congr. Latino-Am. Paleontol., Porto Alegre, RS, Anais, 1:233-247.

DOLIANITI, E. (1945) Um novo elemento na flora fóssil do Brasil, "Sphenozamites" Brongniart. DGM, DNPM, Nota Prelim. Est., 26:1-4.

DOLIANITI, E. (1952) La flore fossile du Gondwana au Brésil d'après sa position stratigraphique. $19^{\text {ème }}$ Congr. Géol. Int., Symp. Sér. Gondwana, Alger, p. 285-292.

GORDON-GRAY, K.D.; VAN DIJK, D.E.; LACEY, W.S. (1976). Preliminary report on equisetalean plants from Lidgetton, Natal. Palaeont. Afric., 19:43-57.

MENDES, J.C. (1954) Contribuiçâo à estratigrafia da Série Passa Dois no Estado do Paraná. Bol. Fac. Fil. Ciêne. Letr., Univ. São Paulo, 175 (Geol, 10), 119p.

MILLAN, J.H. (1977) Moldes medulares da tafoflórula gondwânica de Monte Mor, Estado de São Paulo. An. Acad. brasil. Ciênc., 49(4):195-204.

OLIVEIRA, E.P. (1918) Anexo. In: Holdhaus, K., Sobre alguns lamelibrânquios fósseis do sul do Brasil. Rio de Ja. neiro, Serv. Geol. Miner., Monogr., 2:27-32.

PANT, D.D. \& KIDWAI, P.F. (1968) On the structure of stems and leaves of Phyllotheca indica Bunbury, and its affinities. Palaeontogr., Abt.B, 121(4-6):102-121, pls. 30-33

RENAULT, M.B. (1895) Notice sur les Calamariées. Bull. Soc. Hist. Nat. Autun, 8:1-54, 7 pls.

RENAULT, M.B. (1896) Notice sur les Calamariées. II. Bull. Soc. Hist. Nat. Autun, 9:305-354, 13 pls.

RIGBY, J.F. (1966) The Lower Gondwana floras of the Perth and Collie Basins, Western Australia. Palaeontogr., Abt B, 118(4-6):113-152, pls. 30-36.

RIGBY, J.F. (1969) Permian sphenopsids from Antarctica. Contributions to Paleontology, 1968, U.S. Geol. Surv. Prof. Pap., 613-F, 13 p., 3 pls.

RIGBY, J.F. (1970) The distribution of Lower Gondwana plants in the Parana Basin of Brazil. 2nd Gondwana Symp., Pretoria, Proc. and Pap., p. 575-584.

ROHN, R. \& RÖSLER, O. (1986) Schizoneura gondwanensis Feistmantel da Formaçâo Rio do Rasto (Bacia do Paraná, Permiano Superior) no Estado do Paraná e no norte do Estado de Santa Catarina. Neste volume.

RÖSLER, O. \& ROHN, R. (1984) Sphenophyllum paranaense n. sp. (Sphenophyta) da Formaçáo Rio do Rasto (Permiano Superior) de Dorizon, Estado do Paraná. Bol IG-USP, 15:97-104.

ZALESSKY, M.D. (1927) Flore permienne des limites euraliennes de l'Angaride. Com. russ. geol. Mem., Leningrado, 176:1-52. 